\title{
Performance assessment of integrated energy systems for the production of renewable hydrogen energy carriers
}

\author{
Francesco Lonis ${ }^{1,},{ }^{*}$ Vittorio Tola ${ }^{1}$, and Giorgio Cau ${ }^{1}$ \\ ${ }^{1}$ Department of Mechanical, Chemical and Materials Engineering, University of Cagliari, Via \\ Marengo 2, 09123 Cagliari, Italy
}

\begin{abstract}
To guarantee a smooth transition to a clean and low-carbon society without abandoning all of a sudden liquid fuels and products derived from fossil resources, power-to-liquids processes can be used to exploit an excess of renewable energy, producing methanol and dimethyl ether (DME) from the conversion of hydrogen and recycled $\mathrm{CO}_{2}$. Such a system could behave as an energy storage system, and/or a source of fuels and chemicals for a variety of applications in several industrial sectors.

This paper concerns the conceptual design, performance analysis and comparison of small-scale decentralised integrated energy systems to produce methanol and DME from renewable hydrogen and captured $\mathrm{CO}_{2}$. Renewable hydrogen is produced exploiting excess RES. Water electrolysis is carried out considering two different technologies alternatively: commercially mature low temperature alkaline electrolysers (AEL) and innovative high temperature solid oxide electrolysers (SOEC). A first conversion of hydrogen and $\mathrm{CO}_{2}$ takes place in a catalytic reactor where methanol is synthesised through the hydrogenation process. Methanol is then purified in a distillation column. Depending on the final application, methanol can be further converted into DME through catalytic dehydration in another catalytic reactor. The chemical (either methanol or DME) is stored at ambient conditions and used as necessary.

To predict the performance of the main components and of the overall system, numerical simulation models were developed using the software Aspen Plus. The performance and efficiencies of each section and of the overall systems were evaluated through extensive mass and energy balances. Globally, the overall power-to-liquids efficiency was found to be above 0.55 for all the different configurations, both considering a powerto-methanol or a power-to-DME process.
\end{abstract}

\section{Nomenclature}

\begin{tabular}{llll}
\hline AEL & Alkaline electrolyser & MSS & Methanol synthesis section \\
CCU & Carbon capture and utilization & PtL & Power-to-liquids \\
DME & Dimethyl ether & PtX & Power-to-X \\
DSS & Dimethyl ether synthesis section & RES & Renewable energy sources \\
MeOH & Methanol & SOEC & Solid oxide electrolyser cell \\
\hline
\end{tabular}

*Corresponding author: francesco.lonis@unica.it 


\section{Introduction}

Nowadays, climate change strictly related to $\mathrm{CO}_{2}$ emissions is one of the most daunting problems within the energy sector. Different solutions, such as exploiting renewable energy sources, applying carbon capture and storage technologies, improving the energy efficiency of existing processes, and reducing the overall energy consumption, can be employed to minimize the impact of the human activities on the environment. A promising solution of increasing interest is the carbon capture and utilisation (CCU), where carbon dioxide is captured from point sources such as energy intensive industries or centralised power plants and is recycled to useful products such as fuels and chemical compounds with near-to-zero net $\mathrm{CO}_{2}$ emissions $[1,2]$. In future perspective, it would be even possible to capture the $\mathrm{CO}_{2}$ from air directly.

Carbon dioxide can be converted into useful products along with hydrogen. To guarantee clean products derived from $\mathrm{CO}_{2}$, the hydrogen employed in such processes should come from renewable energy sources. Power-to-X $(\mathrm{PtX})$ technologies and processes are based on such an approach: RES are used to produce renewable hydrogen through water electrolysis, and $\mathrm{CO}_{2}$ and hydrogen are reacted following several ways (e.g. $\mathrm{CO}_{2}$ hydrogenation, Fischer-Tropsch conversion, Mobil process, etc.) into a variety of products. The "X" refers to liquid and gaseous fuels (power-to-liquids PtL, and power-to-gas PtG, respectively), as well as chemical compounds of different nature [3]. Indeed, PtX can be employed to recycle carbon dioxide into green products to be used in several sectors, providing a variety of commodities [1,3]: production of hydrogen and hydrogen carriers [4], fuels for power generation and combined heat and power [2], heat production [5], transportation [6,7], energy storage and grid ancillary services as well as grid balancing $[8,9]$, production of chemical compounds and fuels (i.e. methanol, dimethyl ether DME, formaldehyde, gasoline, diesel fuel, methane, syngas, jet fuel, etc.) [10,11]. PtX technologies represent an opportunity of improving RES penetration and diffusion, boosting their exploitation while providing a solution to store excess energy in long-term, high-energy, highly stable compounds, and creating a closed carbon cycle [12,13]. Several examples of studies regarding PtX systems can be found in literature (e.g. [6,14-18]). Typical compounds produced in the chemical industry are derived from fossil fuels and produced through steam methane reforming or conversion of other hydrocarbons by gasification to syngas. Several of these compounds could be substituted by low-carbon counterparts through PtX applications [10,11].

Within this context, the present work is focused on the analysis of two energy systems based on the PtL technology where clean hydrogen produced from RES is converted into methanol and/or dimethyl ether (DME) [19]. Methanol and DME production takes place through $\mathrm{CO}_{2}$ hydrogenation and methanol dehydration, respectively, in two different catalytic reactors. Two different electrolysis technologies were considered, i.e. alkaline water electrolysis and solid oxide electrolysis. Clean hydrogen and captured $\mathrm{CO}_{2}$ are compressed and heated to the operating conditions of the methanol reactor. Following the purification of the water/methanol mixture, methanol can be further converted into DME in a second reactor. Then, dimethyl ether is purified in a distillation column.

Methanol and DME are hydrogen carriers, the former being liquid at ambient conditions and the latter being in gaseous form. Methanol is typically used in the synthesis and blending of fuels and in the synthesis of commodity chemicals. It is also used directly as a fuel both in fuel cells and internal combustion engines, in organic synthesis processes, as a solvent, antifreeze liquid, in ethanol denaturation, and in the production of biodiesel by transesterification. Many processes are based on the conversion of methanol: formaldehyde production, methanol to hydrocarbons, to olefins, and to gasoline (MTO/MTP process). Methanol is also used in the making of synthetic fibres for clothes, in the production of 
adhesives, paints, and as a chemical agent in the pharmaceutical and agrichemical sectors [11]. Dimethyl ether is used as a fuel in diesel engines with minor modifications in the engine architecture, as a building block for chemicals such as ethylene and propylene and as a substitute for chlorofluorocarbons. Not having C-C bonds, it is a rather clean fuel with lower emissions of NOx and particulate matter and no SOx emissions than the conventional diesel fuel [20]. Furthermore, DME is used as a replacement for propane in liquefied petroleum gas (LPG) and is employed in the production of several chemical compounds [21]. Finally, using such liquid fuels (i.e. methanol at ambient conditions or pressurised DME) would solve many issues that would arise in the case of a hydrogen economy, such as storage, handling and transportation, and safety [22].

In this work, excess of renewable energy is supposed to be available without limitations, even though a proper RES load diagram should be taken into account to analyse the actual behaviour of this kind of systems.

\section{System description and modelling}

\subsection{General configuration}

The general configuration of the overall system mainly includes a water electrolysis section and two chemical conversion sections. In the first, methanol is produced through $\mathrm{CO}_{2}$ hydrogenation. In the second, DME is synthesised following methanol dehydration.

Figure 1 shows a simplified functional scheme of the overall system.

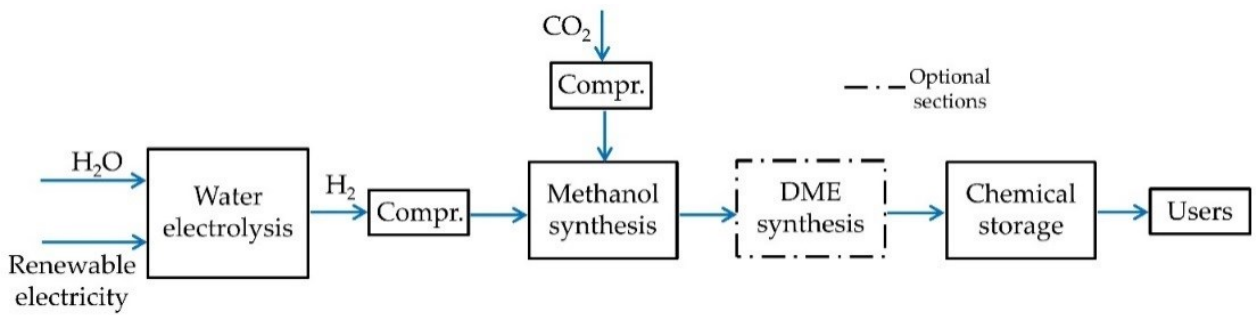

Fig. 1. Simplified functional scheme of the overall system

Water and renewable electricity feed an electrolyser and the produced hydrogen is compressed, along with $\mathrm{CO}_{2}$, to the operating conditions of the methanol synthesis section (MSS). Methanol is synthesised following the catalytic $\mathrm{CO}_{2}$ hydrogenation process. Methanol can be further converted into DME in a second conversion section where catalytic methanol dehydration is carried out. Dimethyl ether production could be either achieved in a two-step or in a one-step process: in the former, firstly methanol is produced (typically from syngas) and then is dehydrated to DME; in the latter, methanol and DME production is carried out in the same reactor [17]. Since the two-step is the most developed process, it was chosen in this work. In addition, depending on the final user, methanol or DME production might be privileged over the other. By using a two-step approach through the exploitation of two different reactors it is possible to vary the production of the two feedstocks without the constraint of one single reactor [17].

Considering the only existing commercial renewable methanol plant as a reference (George Olah Plant $[23,24]$ ), the systems in this work are sized to produce approximately $500 \mathrm{~kg} / \mathrm{h}$ of methanol. The produced methanol can be further converted into $360 \mathrm{~kg} / \mathrm{h}$ of DME. The flow rates of the streams feeding the electrolyser and the methanol synthesis section are calculated accordingly. 


\subsection{Modelling of main processes}

\subsubsection{Water electrolysis}

To perform the electrolysis of water two different technologies were compared: lowtemperature alkaline electrolysis (AEL) and high-temperature solid oxide electrolysis (SOEC). On the one hand, the former is already largely diffused and commercially available. On the other hand, the latter is characterised by a technology readiness level (TRL, i.e. a scale used to estimate the maturity of a technology in a scale from 1, basic research, to 9, actual system proven in operational environment [25]) of 6-7 that is expected to have reached the maximum value of 9 by the 2030 [26]. Nevertheless, high temperature electrolysis is characterised by significantly lower electricity consumption compared to low temperature electrolysis. Indeed, when the temperature of the electrolysis increases, a remarkable quantity of electric energy is substituted by thermal energy, reducing the consumption of high-quality energy and improving the efficiency of the process [27]. The overall energy required in the electrolysis slightly increases with temperature. Thus, because of the high temperature operation, SOECs are capable of significantly higher efficiencies compared to alkaline electrolysers, allowing a remarkable reduction in electricity consumption. Indeed, high temperature operation reduces the electrochemical losses because of better reaction kinetic and lower overvoltages.

In this work, both electrolysis models are purposely adapted and implemented in Aspen Plus through user-defined blocks. Alkaline water electrolysis, simulated with an electrochemical model developed from the equations provided by Ursua and Sanchis [28], is carried out at $65^{\circ} \mathrm{C}$ and 25 bar. On the other hand, solid oxide electrolysis is carried out at $850{ }^{\circ} \mathrm{C}$ and 1 bar, and simulated through an electrochemical model developed from the equations reported by $\mathrm{Ni}$ et al. [29,30]. The extensive adapted models are reported elsewhere $[31,32]$.

The AEL model developed in Aspen Plus just consists of a few streams, a reactor where the electrolysis reaction is carried out, and a heat exchanger. Water is pumped from ambient pressure to 25 bar and is preheated from 25 to $65{ }^{\circ} \mathrm{C}$. The water enters the electrolyser and hydrogen and oxygen at 25 bar are produced. Since the electrolysis is an exothermic process, the heat produced within the electrolyser is employed to preheat the feed water and no external heat is needed.

The SOEC model is more complex because of extensive heat transfer and recovery that can be performed inside it to improve the overall efficiency.

Figure 2 shows the simplified functional scheme of the alkaline and solid oxide electrolysers.

On the anode side of the SOEC, the sweep air $\left(4 \mathrm{E}_{\mathrm{S}}\right)$ is heated $\left(\mathrm{HX} 4 \mathrm{E}_{\mathrm{S}}\right)$ from ambient temperature to $800{ }^{\circ} \mathrm{C}$ exploiting the heat contained in the exhaust air $\left(6 \mathrm{E}_{\mathrm{S}}\right)$, rich in oxygen, exiting the stack at $850^{\circ} \mathrm{C}$. This heat recovery process allows saving $270 \mathrm{~kW}$. After, hot air must still be heated $\left(\mathrm{H}_{3} \mathrm{E}_{\mathrm{S}}\right)$ from 800 to $850{ }^{\circ} \mathrm{C}$ requiring $19 \mathrm{~kW}$ provided by an external heat source, or directly retrieved from the exothermicity of SOEC electrochemical reactions. On the cathode side, water $\left(1 \mathrm{E}_{\mathrm{S}}\right)$ must be preheated, vaporised and superheated to the operating temperature. A portion of the water $(255$ out of $920 \mathrm{~kg} / \mathrm{h})$ is preheated and vaporised $(183 \mathrm{~kW})$ using the residual heat of the hot anode exhaust $\left(\mathrm{HX} 1 \mathrm{E}_{\mathrm{S}}\right)$ after that the inlet air preheating is carried out. To reach saturation, the remainder requires $578 \mathrm{~kW}$ provided by an external source (HX2Es). Saturated steam is superheated up to $685{ }^{\circ} \mathrm{C}$ (HX3Es) absorbing heat $(356 \mathrm{~kW})$ from the cathode exhaust $\left(10 \mathrm{E}_{\mathrm{S}}\right)$ composed of hydrogen and water. A further $115 \mathrm{~kW}$ is necessary to conclude the superheating process (H4E $)$ from $685{ }^{\circ} \mathrm{C}$ to $850{ }^{\circ} \mathrm{C}$. This heat is provided by the exothermicity of the electrochemical reactions within the stack. 


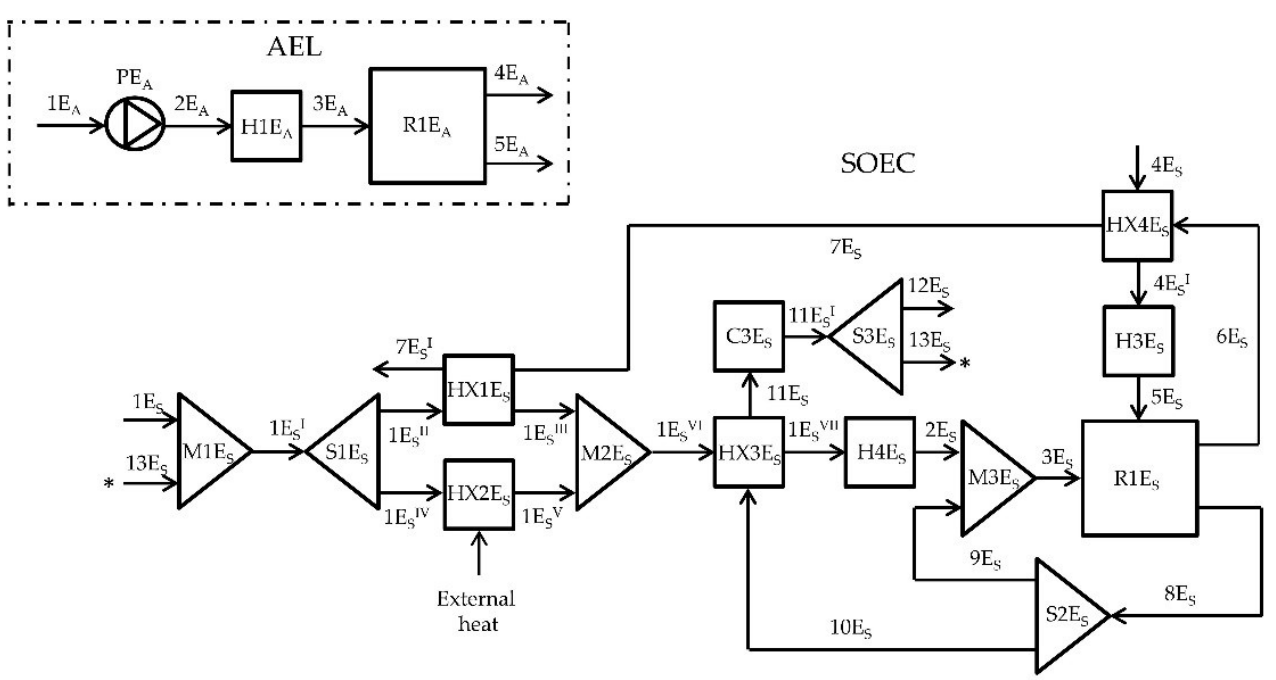

Fig. 2. Simplified functional scheme of the electrolysis processes (AEL left upper corner within the dashed-line area, SOEC right lower corner)

In the SOEC, the water utilization factor was assumed equal to 0.85, and the SOEC inlet feed is a mixture of water and hydrogen ( $90 \%$ and $10 \%$, respectively) to avoid electrode oxidation [33]. Following the preheating process, the unreacted water is separated from the hydrogen and recycled back to the inlet $\left(13 \mathrm{E}_{\mathrm{S}}\right)$.

In the electrolysis section approximately $920 \mathrm{~kg} / \mathrm{h}$ of water are converted into $102 \mathrm{~kg} / \mathrm{h}$ of hydrogen. To carry out the electrolysis, the AEL and the SOEC require approximately 4.7 MW and 3.4 MW, respectively.

\subsubsection{Methanol synthesis and purification}

The MSS is mainly composed of an adiabatic catalytic reactor and a distillation column [34]. Inside the reactor methanol is produced through the $\mathrm{CO}_{2}$ hydrogenation process, following the reverse water gas shift reaction (1), the $\mathrm{CO}$ hydrogenation reaction (2), and the $\mathrm{CO}_{2}$ hydrogenation reaction (3):

$$
\begin{aligned}
& \mathrm{CO}_{2}+\mathrm{H}_{2} \rightleftarrows \mathrm{CO}+\mathrm{H}_{2} \mathrm{O} \\
& \mathrm{CO}+2 \mathrm{H}_{2} \rightleftarrows \mathrm{CH}_{3} \mathrm{OH} \\
& \mathrm{CO}_{2}+3 \mathrm{H}_{2} \rightleftarrows \mathrm{CH}_{3} \mathrm{OH}+\mathrm{H}_{2} \mathrm{O}
\end{aligned}
$$

To simulate the methanol synthesis process a Langmuir-Hinshelwood Hougen-Watson (LHHW) kinetic model [34] was implemented in an Aspen Plus user-defined function using an RPlug reactor [35]. The reactor is composed of 34 tubes characterised by a length of $12.2 \mathrm{~m}$ and a diameter of $0.0375 \mathrm{~m}$. The bed voidage is 0.4 and the particle density 1775 $\mathrm{kg} / \mathrm{m}^{3}$ [34].

Methanol production is set equal to $500 \mathrm{~kg} / \mathrm{h}$ as in the George Olah Plant. From this value, the flow rates of hydrogen and carbon dioxide are calculated. In particular, assuming a molar ratio of $\mathrm{CO}_{2}$ hydrogenation equal to the stoichiometric one, and recycling the $\mathrm{CO}_{2}$ exiting the distillation column to the inlet, a fresh flow rate of hydrogen equal to approximately $100 \mathrm{~kg} / \mathrm{h}$ and of $\mathrm{CO}_{2}$ equal to around $715 \mathrm{~kg} / \mathrm{h}$ are necessary.

Both feedstocks are separately compressed up to 65 bar. The configuration of the hydrogen compression section depends on the adopted electrolysis technology. Since the 
alkaline electrolysis is carried out at 25 bar, only one compressor is required for the AELbased configuration. On the other hand, since solid oxide electrolysis is carried out at ambient pressure, 3 intercooled compressors (intercooler temperature set equal to $38{ }^{\circ} \mathrm{C}$ ) are employed in the SOEC-based configuration. The compression of the $\mathrm{CO}_{2}$ is carried out through 3 compressors as well. The hydrogen compressors absorb $51 \mathrm{~kW}$ (AEL configuration), or $183 \mathrm{~kW}$ (SOEC configuration) while the $\mathrm{CO}_{2}$ compressors absorb 75 $\mathrm{kW}$.

The compressed $\mathrm{H}_{2}$ and $\mathrm{CO}_{2}$ are preheated (HX1M) up to $210{ }^{\circ} \mathrm{C}$, before entering the adiabatic reactor $(\mathrm{R} 1 \mathrm{M})$, where the temperature rises to $290{ }^{\circ} \mathrm{C}$. Then, the reactor exhaust gases $(15 \mathrm{M})$ are cooled, both preheating a variety of streams within the section and providing the distillation reboiling heat to reduce the overall energy requirements. Two flash processes (performed at $50{ }^{\circ} \mathrm{C}$ and 65 bar the first $\left(\mathrm{F} 1 \mathrm{M}\right.$ ), and at $22{ }^{\circ} \mathrm{C}$ and 1.2 bar the second (F2M)) are employed to separate the unreacted compounds and incondensable gases from the liquid mixture of methanol and water (namely crude methanol, $48.7 \%$ vol. methanol and $49.4 \%$ vol. water).

Subsequently, a purification process is carried out: firstly, the crude methanol is heated to $80{ }^{\circ} \mathrm{C}$, then, it enters a distillation column (D1M) where high purity methanol $\left(96.4 \% \%_{\text {vol }}\right.$. methanol and $3.6 \% \%_{\mathrm{vol}} . \mathrm{CO}_{2}$ ) is distilled guaranteeing the complete separation of methanol (distillate) from water (bottoms). The distillate is then cooled, allowing condensing and separating methanol from $\mathrm{CO}_{2}$ that is mixed with the fresh $\mathrm{CO}_{2}$ at the inlet. The main geometric and operating parameters are reported in Table 1. A detailed description of the process is reported in [31].

The chosen configuration allows the recovery of a large amount of heat inside the section. The reactants preheating process requires around $430 \mathrm{~kW}$, cooling the reactor products from 285 to $163{ }^{\circ} \mathrm{C}(\mathrm{HX} 1 \mathrm{M})$. The reboiling heat in the distillation column is equal to around $240 \mathrm{~kW}$ and causes a further reduction of the temperature of the products to 120 ${ }^{\circ} \mathrm{C}\left(15 \mathrm{M}^{\mathrm{II}}\right)$. Finally, the products are cooled to $100{ }^{\circ} \mathrm{C}$ allowing the crude methanol heating from $22{ }^{\circ} \mathrm{C}$ (second flash outlet temperature) to $80{ }^{\circ} \mathrm{C}$ (distillation column inlet temperature) recovering around $180 \mathrm{~kW}(\mathrm{HX} 2 \mathrm{M})$. Another $330 \mathrm{~kW}$ should be removed to reach the temperature imposed in the first flash $(\mathrm{C} 2 \mathrm{M})$.

Figure 3 shows the simplified flowsheet of both the MSS and the DSS.

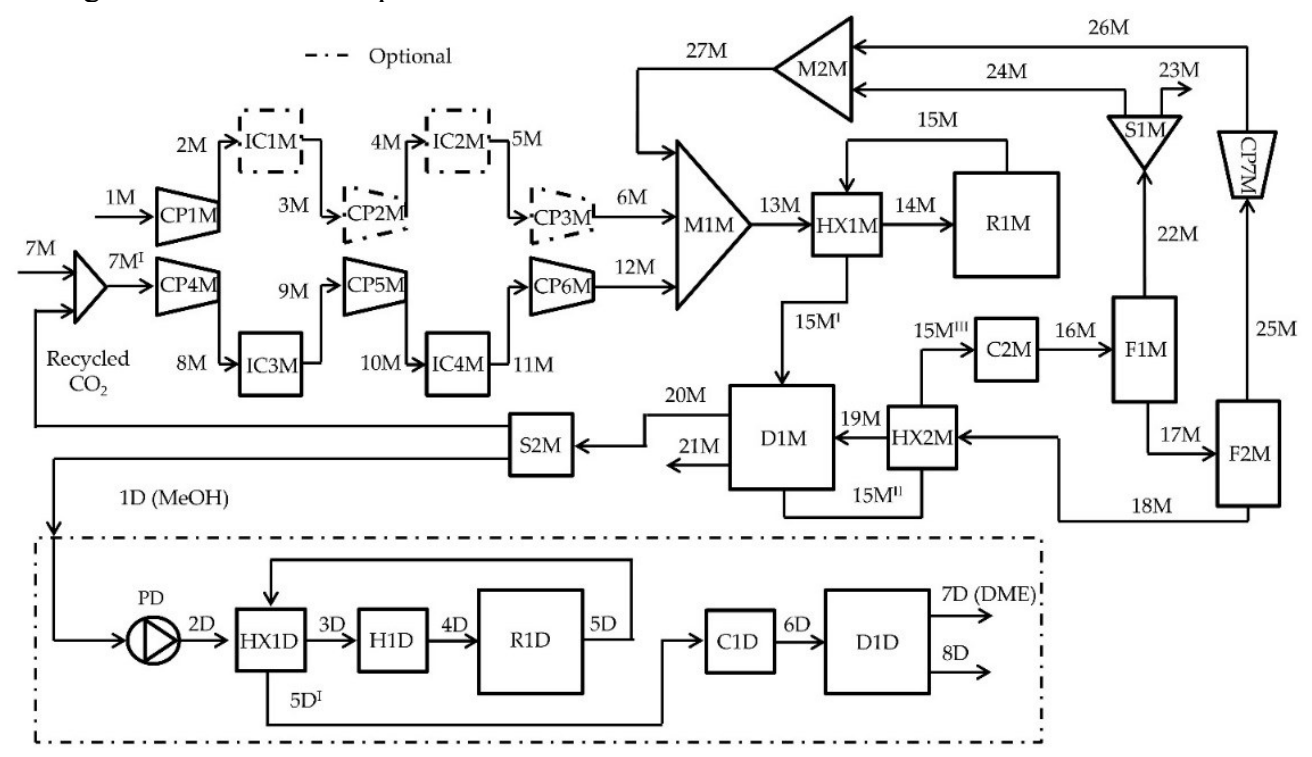

Fig. 3. Simplified functional scheme of the chemical synthesis sections 


\subsubsection{Dimethyl ether synthesis and purification}

Depending on the final use and application, it is possible to convert methanol into dimethyl ether in a second synthesis and purification section. The main blocks in the DME synthesis section are a kinetic reactor and a distillation column. Dimethyl ether is synthesised following the methanol dehydration reaction (4):

$$
2 \mathrm{CH}_{3} \mathrm{OH} \rightleftarrows \mathrm{CH}_{3} \mathrm{OCH}_{3}+\mathrm{H}_{2} \mathrm{O}
$$

The catalytic reaction is carried out over an amorphous alumina catalyst treated with $10.2 \%$ silica [35]. The inlet temperature and operating pressure of the reactor are set at 250 ${ }^{\circ} \mathrm{C}$ and 17 bar, respectively, leading to no significant side reactions, and assuring the reactor to be kinetically controlled. The model of the reactor is developed from the power-law kinetic equation reported in Al-Malah [35]. The model is implemented within an RPlug reactor composed of 27 tubes, characterised by a length of $12.2 \mathrm{~m}$ and a diameter of 0.0375 $\mathrm{m}$. The bed voidage is set equal to 0.5 and the particle density to $4000 \mathrm{~kg} / \mathrm{m}^{3}$ [35]. These operating conditions assures the complete conversion of $500 \mathrm{~kg} / \mathrm{h}$ of methanol [35], leading to a production of approximately $360 \mathrm{~kg} / \mathrm{h}$ of dimethyl ether.

Methanol leaves the MSS at $60{ }^{\circ} \mathrm{C}$ and 1 bar and is brought to the DME reactor conditions $\left(250{ }^{\circ} \mathrm{C}, 17\right.$ bar $)$ through a pump and a heat exchanger. Since methanol dehydration is an exothermic reaction and the reactor is assumed adiabatic, the temperature of the products rises sensibly (up to about $400{ }^{\circ} \mathrm{C}$ ). The reactor products (around $50 \%$ vol. for both $\mathrm{DME}$ and water, with traces of methanol) are firstly cooled to $116{ }^{\circ} \mathrm{C}$, recovering around $190 \mathrm{~kW}$ to heat the inlet methanol from $60{ }^{\circ} \mathrm{C}$ to $236{ }^{\circ} \mathrm{C}$ (HX1D), and then expanded to 10 bar after being cooled to $82{ }^{\circ} \mathrm{C}$ to avoid evaporation in the expansion step. To heat the methanol to $250{ }^{\circ} \mathrm{C}$, around $4 \mathrm{~kW}$ are provided in a heater (H1D). The DME distillation column guarantees the complete separation of dimethyl ether (distillate) from water (bottoms) with a distillate purity of $99.99 \%$. The required reboiling heat is equal to $178 \mathrm{~kW}$. The DME leaves the column at $43{ }^{\circ} \mathrm{C}$ and 9.5 bar, and it is stored in liquid form at $30{ }^{\circ} \mathrm{C}$.

Table 1 summarises the characteristics of the distillation columns employed in the methanol and dimethyl ether synthesis sections.

Table 1. Parameters of the distillation columns

\begin{tabular}{lcc}
\hline \multicolumn{1}{c}{ Parameter } & MSS & DSS \\
\hline Operating pressure [bar] & 1.01 & 9.5 \\
Number of stages & 37 & 15 \\
Feed stage & $24^{\text {th }}$ & $6^{\text {th }}$ \\
Reflux ratio (molar) & 1.2 & 3.3 \\
Bottoms to feed ratio (molar) & 0.5 & N/A \\
Distillate to feed ratio (molar) & N/A & 0.5 \\
\hline
\end{tabular}

\subsection{Performance Indices}

Special energy indices were defined to evaluate the performance of the single sections and of the overall systems and to compare the two configurations. The performance indices were arranged in such a manner that correlations between the indices can be obtained by their manipulation. Similar indices are reported in other works from the same authors $[31,32]$. 
The efficiency of the water electrolysis is defined by Eq. (5), where $\dot{m}_{\mathrm{H}_{2}}$ is the hydrogen mass flow, $L H V_{H_{2}}$ is the lower heating value of hydrogen, $P_{\text {ele }}$ the power required to carry out the electrolysis of water and $P_{B O P, e l e}$ the balance of plant.

$$
\eta_{\text {ele }}=\frac{\dot{m}_{\mathrm{H}_{2}} \cdot \mathrm{LHV}_{\mathrm{H}_{2}}}{P_{\text {ele }}+P_{B O P, e l e}}
$$

The efficiency of the MSS (Eq. (6)) is defined as the ratio between the chemical power of the produced methanol and the power provided under the form of hydrogen chemical power $\left(\dot{m}_{H_{2}} \cdot L H V_{H_{2}}\right)$, electric power $\left(P_{B O P, M S S}\right)$, and heat $\left(\dot{E}_{M S S}\right)$.

$$
\eta_{M S S}=\frac{\dot{m}_{M e O H} \cdot L H V_{M e O H}}{\dot{m}_{H_{2}} \cdot L H V_{H_{2}}+P_{B O P, M S S}+\dot{E}_{M S S}}
$$

To consider the two systems connected and in synergy, and to obtain proper and reliable correlations, three intermediate performance indices were defined in this work. A methanol synthesis section efficiency defined similarly to a cold gas efficiency of a gasifier (Eq. (7)):

$$
\eta_{M S S, C}=\frac{\dot{m}_{M e O H} \cdot L H V_{M e O H}}{\dot{m}_{\mathrm{H}_{2}} \cdot L H V_{H_{2}}}
$$

The term $\varphi_{\text {ele,MSS }}$, that represents the ratio between the power entering the electrolysis section and the total power entering the system (Eq. (8)):

$$
\varphi_{\text {ele }, M S S}=\frac{P_{\text {ele }}+P_{B O P, e l e}}{P_{\text {ele }}+P_{B O P, e l e}+P_{B O P, M S S}+\dot{E}_{M S S}}
$$

A rectified efficiency of the electrolysis $\left(\eta_{\text {ele } R, M S S}\right)$, that represents the efficiency the electrolyser would have if it was powered also with the power entering the MSS, returning this power in full to the MSS along with the produced hydrogen (Eq. (9)).

$$
\eta_{e l e, R, M S S}=\frac{\dot{m}_{H_{2}} \cdot L H V_{H_{2}}+\left(P_{B O P, M S S}+\dot{E}_{M S S}\right)}{P_{\text {ele }}+P_{B O P, e l e}+\left(P_{B O P, M S S}+\dot{E}_{M S S}\right)}
$$

Finally, a power-to-liquids efficiency $\eta_{P t L, M S S}$ is defined as the ratio between the chemical power of the produced methanol and the power provided in all the conversion processes (electricity and heat in the electrolysis and synthesis). The PtL efficiency, reported in Eq. (10), can be also expressed using the intermediate terms defined previously:

$$
\eta_{P t L, M S S}=\frac{\dot{m}_{M e O H} \cdot L H V_{M e O H}}{P_{e l e}+P_{B O P, e l e}+P_{B O P, M S S}+\dot{E}_{M S S}}=\eta_{e l e} \cdot \varphi_{e l e, M S S} \cdot \eta_{M S S, C}=\eta_{e l e, R, M S S} \cdot \eta_{M S S}
$$

Similar equations are defined also for the synthesis of the dimethyl ether, considering the addition of the DSS as an appendix of the MSS (see Fig. 3). For instance, Eq. (11) represents the efficiency of the dimethyl ether synthesis embodying the conversion process from hydrogen to methanol. Thus, it is expressed as the ratio between the chemical power of the DME $\left(\dot{m}_{D M E} \cdot L H V_{D M E}\right)$ and the power provided to the overall methanol and dimethyl ether synthesis section $\left(\dot{m}_{H_{2}} \cdot L H V_{H_{2}}\right.$ hydrogen chemical power, $P_{B O P, M S S}+\dot{E}_{M S S}$ methanol synthesis external power, $P_{B O P, D S S}+\dot{E}_{D S S}$ dimethyl ether synthesis external power).

$$
\eta_{D S S}=\frac{\dot{m}_{D M E} \cdot L H V_{D M E}}{\dot{m}_{H_{2}} \cdot L H V_{H_{2}}+P_{B O P, M S S}+\dot{E}_{M S S}+P_{B O P, D S S}+\dot{E}_{D S S}}
$$

In the same way, a cold gas efficiency can also be evaluated for the dimethyl ether synthesis, where the ratio between DME and hydrogen is considered (Eq. (12)): 


$$
\eta_{D S S, C}=\frac{\dot{m}_{D M E} \cdot L H V_{D M E}}{\dot{m}_{H_{2}} \cdot L H V_{H_{2}}}
$$

Equation (13) corresponds to Eq. (8) defined in the case of the methanol synthesis.

$$
\varphi_{e l e, D S S}=\frac{P_{e l e}+P_{B O P, e l e}}{P_{e l e}+P_{B O P, e l e}+P_{B O P, M S S}+\dot{E}_{M S S}+P_{B O P, D S S}+\dot{E}_{D S S}}
$$

Equation (14) is a rectified electrolysis efficiency for the case of dimethyl ether production.

$$
\eta_{e l e, R, D S S}=\frac{\dot{m}_{H_{2}} \cdot L H V_{H_{2}}+\left(P_{B O P, M S S}+\dot{E}_{M S S}\right)+\left(P_{B O P, \mathrm{DSS}}+\dot{E}_{D S S}\right)}{P_{e l e}+P_{B O P, e l e}+\left(P_{B O P, M S S}+\dot{E}_{M S S}\right)+\left(P_{B O P, \mathrm{DSS}}+\dot{E}_{D S S}\right)}
$$

Finally, a power-to-liquids efficiency of the dimethyl ether section is defined as Eq. (15):

$$
\begin{gathered}
\eta_{P t L, D S S}=\frac{\dot{m}_{D M E} \cdot L H V_{D M E}}{P_{\text {ele }}+P_{B O P, e l e}+P_{B O P, M S S}+\dot{E}_{M S S}+P_{B O P, \mathrm{DSS}}+\dot{E}_{D S S}}= \\
=\eta_{\text {ele }} \cdot \varphi_{\text {ele }, \mathrm{DSS}} \cdot \eta_{D S S, C}=\eta_{\text {ele }, \mathrm{R}, \mathrm{DSS}} \cdot \eta_{D S S}
\end{gathered}
$$

\section{Results and discussion}

The model described above were used to evaluate the performance indices through extensive energy and mass balances. Table 2 shows, for the main processes of the system, the chemical power of both feedings and products and the electrical power absorbed by the sections.

Table 2. Main results of the sections for the AEL and SOEC systems

\begin{tabular}{ccccc}
\hline Section & Process & AEL & SOEC & \\
\hline \multirow{3}{*}{ Electrolysis } & $\dot{m}_{\mathrm{H}_{2}} \cdot \mathrm{LH} V_{\mathrm{H}_{2}}$ & 3395 & 3395 & $\mathrm{~kW}$ \\
& $P_{\text {ele }}$ & 4690 & 3433 & $\mathrm{~kW}$ \\
& $P_{B O P, e l e}$ & 0.9 & 597 & $\mathrm{~kW}$ \\
\hline \multirow{3}{*}{ Methanol } & $\dot{m}_{\mathrm{MeOH}} \cdot L H V_{M e O H}$ & 2768 & 2768 & $\mathrm{~kW}$ \\
synthesis & $\dot{m}_{\mathrm{H}_{2}} \cdot L H V_{\mathrm{H}_{2}}$ & 3395 & 3395 & $\mathrm{~kW}$ \\
& $P_{B O P, M S S}$ & 126 & 322 & $\mathrm{~kW}$ \\
& $\dot{E}_{M S S}$ & 0 & 0 & $\mathrm{~kW}$ \\
\hline \multirow{2}{*}{ Dimethyl ether } & $\dot{m}_{D M E} \cdot L H V_{D M E}$ & 2889 & 2889 & $\mathrm{~kW}$ \\
synthesis & $\dot{m}_{M e O H} \cdot L H V_{M e O H}$ & 2768 & 2768 & $\mathrm{~kW}$ \\
& $P_{B O P, D S S}$ & 0.3 & 0.3 & $\mathrm{~kW}$ \\
& $\dot{E}_{D S S}$ & 181 & 181 & $\mathrm{~kW}$ \\
\hline
\end{tabular}

Since the AEL operates at lower temperature it requires a higher power (4.7 MW) than the SOEC. Moreover, the BOP is near zero being only related to the feeding water pump. On the other hand, the solid oxide electrolyser requires $600 \mathrm{~kW}$ of external heat to complete the feeding preheating. In the methanol synthesis the conversion of $3.4 \mathrm{MW}$ of hydrogen chemical power into $2.8 \mathrm{MW}$ of methanol chemical power is carried out. The difference in $P_{B O P, M S S}$ between the two configurations is due to the compression section. Indeed, the SOEC operates at ambient pressure requiring a higher compression power for compressing the hydrogen to the MSS operating conditions. The DSS shows the same performance in 
both electrolysis configurations and allows increasing the chemical power of the product from 2.77 (methanol) to $2.89 \mathrm{MW}$ (DME). To do so, it is necessary to provide an external thermal power of around $180 \mathrm{~kW}$ in the methanol preheating and in the distillation processes.

Finally, Table 3 summarises the values of the performance indices for the two cases of methanol and DME synthesis. As already explained, the solid oxide technology is characterised by a higher efficiency $(0.84)$ than the alkaline one $(0.72)$ because of higher operating temperature and lower losses during the electrochemical process. If heat is recovered from another process, the efficiency of the SOEC might even become larger than 0.95 [32]. The efficiency of the methanol synthesis section is slightly larger in the AELbased system $(0.79)$ than in the SOEC one $(0.74)$ due to the lower hydrogen compression power. Globally, the power-to-liquids efficiency $\left(\eta_{P t L, M S S}\right)$ (i.e. the overall plant efficiency) is larger in the SOEC-based system (0.64) than the AEL-based (0.57).

A similar analysis was carried out for dimethyl ether synthesis section. Given the MSS configuration, the production of DME is more efficient when the alkaline electrolysis is employed. Again, however, the efficiency of the overall power-to-liquids system $\left(\eta_{P t L, D S S}\right)$ is larger when the SOEC is used. Indeed, the higher efficiency (more than 10 percentage points) of the electrolysis process compensates the slightly lower efficiency of the chemical conversion section.

It is important to point up that the overall efficiency of the power-to-liquids process is slightly larger for the dimethyl ether synthesis $(0.578$ and 0.637$)$ compared to the methanol synthesis $(0.575$ and 0.636$)$. This is because the process conversion from methanol to dimethyl ether is characterised by a higher efficiency compared to the conversion from hydrogen to methanol, so the global efficiency of the process increases.

Table 3. Performance indices results

\begin{tabular}{cccccc}
\hline \multicolumn{3}{c}{ Methanol synthesis } & \multicolumn{3}{c}{ Dimethyl ether synthesis } \\
\hline Efficiency & Alkaline & Solid oxide & Efficiency & Alkaline & Solid oxide \\
\hline$\eta_{\text {ele }}$ & 0.724 & 0.843 & $\eta_{\text {ele }}$ & 0.724 & 0.843 \\
$\eta_{M S S}$ & 0.786 & 0.745 & $\eta_{D S S}$ & 0.780 & 0.741 \\
$\eta_{M S S, C}$ & 0.815 & 0.815 & $\eta_{D S S, C}$ & 0.851 & 0.851 \\
$\varphi_{\text {ele,MSS }}$ & 0.974 & 0.926 & $\varphi_{\text {ele }, D S S}$ & 0.938 & 0.889 \\
$\eta_{\text {ele }, M S S S}$ & 0.731 & 0.854 & $\eta_{\text {ele }, R, D S S}$ & 0.741 & 0.860 \\
$\eta_{P t L, M S S}$ & 0.575 & 0.636 & $\eta_{P t L, D S S}$ & 0.578 & 0.637 \\
\hline
\end{tabular}

The results obtained in this study are consistent with other PtX solutions based on different processes and final products, showing that both methanol and DME production through the PtX concept are viable solutions with high conversion efficiency. Since SOEC technology is not fully developed yet, its costs are higher than those of alkaline electrolysis. Nevertheless, both technologies show a good overall PtL efficiency. Hence, alkaline electrolysis might be considered as a solution for present time, while SOEC electrolysis should be further developed to reach lower costs and larger diffusion [36].

\section{Conclusions}

In a future decarbonised society, power-to-X technologies powered by RES might play a fundamental role in the provision of low-carbon chemical compounds and fuels to be used in substitution of fossil fuels-derived products. In this paper, a power-to-methanol and a power-to-dimethyl ether plant were analysed. The power-to-DME is simply developed as an appendix of the power-to-methanol with the introduction of a special reactor and distillation column for the production and purification of dimethyl ether. In this concept, 
water feeds an electrolyser and is converted to hydrogen, that reacts along with $\mathrm{CO}_{2}$ to produce methanol in a catalytic reactor. Depending on the considered final user and application, methanol can be stored at ambient conditions after being purified or can be converted into dimethyl ether in a second catalytic reactor.

The electrolysis process absorbs 4.7 MW or 3.4 MW of electric power, depending on the electrolysis technology (alkaline and solid oxide water electrolysis, respectively). Approximately $102 \mathrm{~kg} / \mathrm{h}$ of hydrogen are produced from $920 \mathrm{~kg} / \mathrm{h}$ of water. Hydrogen along with $\mathrm{CO}_{2}$ is converted into $500 \mathrm{~kg} / \mathrm{h}$ of methanol. Methanol can be further converted into $360 \mathrm{~kg} / \mathrm{h}$ of DME. A global power-to-liquids efficiency of around $58 \%$ and $64 \%$ both considering methanol and dimethyl ether production.

Efficiency-wise, the results are consistent with similar PtX concepts found in literature. Presently, the alkaline-based system can be readily deployed while the SOEC-based system should be further developed and should reach a higher technology readiness level from the present value of 6-7 to the maximum 9, associated with commercially ready technologies.

The Research Project was supported by “Fondazione di Sardegna”, CRP project F71I170002800.

\section{References}

1 T. Bossmann, L. Fournié, L. Humberset, P. Khallouf. METIS Study S8 - The role and potential of Power-to-X in 2050. (2018). doi:10.2833/459958.

2 V. Pflug, E. Zindel, G. Zimmermann, O.R. Olvera, I. Pyc, C. Trulley. Power-to-X: The crucial business on the way to a carbon-free world. Tech Pap Siemens AG:1-26 (2019)

3 A. Sternberg, A. Bardow. Power-to-What?-Environmental assessment of energy storage systems. Energy Environ Sci 8:389-400 (2015) doi:10.1039/c4ee03051f.

4 Power-to-X solutions. Innov Landsc a Renewable-Powered Futur Solut to Integr Var $\begin{array}{llll}\text { Renewables } & 1-8 & \text { (2019) https://irena.org/- }\end{array}$ /media/Files/IRENA/Agency/Topics/Innovation-and-

Technology/IRENA_Landscape_Solution_11.pdf?la=en\&hash=2BE79AC597ED18A9 6E5415942E0B93232F82FD85 (accessed November 9, 2019).

5 A. Bloess, W.P. Schill, A. Zerrahn. Power-to-heat for renewable energy integration: A review of technologies, modeling approaches, and flexibility potentials. Appl Energy 212:1611-26 (2018) doi:10.1016/j.apenergy.2017.12.073.

6 P. Schmidt, C. Batteiger, A. Roth, W. Weindorf. Power-to-Liquids as Renewable Fuel Option for Aviation: A Review 127-40 (2018) doi:10.1002/cite.201700129.

7 S. Schemme, R. Can, R. Peters, D. Stolten. Power-to-fuel as a key to sustainable transport systems - An analysis of diesel fuels produced from $\mathrm{CO} 2$ and renewable electricity. Fuel 205:198-221 (2017) doi:10.1016/j.fuel.2017.05.061.

8 C. Bergins, K.C. Tran, S. Wu, E. Kakaras, T. Buddenberg, Ó Sigurbjörnsson, et al. The Challenge of Energy Storage in Europe: Focus on Power to Fuel. J Energy Resour Technol 138:042002 (2016) doi:10.1115/1.4032544.

9 C. Bassano, P. Deiana, L. Lietti, CG. Visconti. P2G movable modular plant operation on synthetic methane production from $\mathrm{CO} 2$ and hydrogen from renewables sources. Fuel 253:1071-9 (2019) doi:10.1016/j.fuel.2019.05.074.

10 B.R. de Vasconcelos, J.M. Lavoie. Recent advances in power-to-X technology for the production of fuels and chemicals. Front Chem 7:1-24 (2019) doi:10.3389/fchem.2019.00392. 
11 M. Bertau, H. Offermanns, L. Plass, F. Schmidt. Methanol: The Basic Chemical and Energy Feedstock of the Future. 2014. doi:10.1007/978-3-642-39709-7.

12 J.A. Baak, A.K. Pozarlik, M.J. Arentsen, G. Brem. Techno-economic study of a zeroemission methanol based energy storage system. Energy Convers Manag 182:530-45 (2019) doi:10.1016/j.enconman.2018.12.015.

13 I. Ganesh. Conversion of carbon dioxide into methanol - A potential liquid fuel: Fundamental challenges and opportunities (a review). Renew Sustain Energy Rev 31:221-57 (2014) doi:10.1016/j.rser.2013.11.045.

14 F.G. Albrecht, D.H. Konig, R.U. Dietrich. The potential of using power-to-liquid plants for power storage purposes. Int Conf Eur Energy Mark EEM 2016;(2016-July). doi:10.1109/EEM.2016.7521203.

15 M. Fasihi, D. Bogdanov, C. Breyer. Techno-Economic Assessment of Power-toLiquids (PtL) Fuels Production and Global Trading Based on Hybrid PV-Wind Power Plants. Energy Procedia 99:243-68 (2016) doi:10.1016/j.egypro.2016.10.115.

16 S. Michailos, S. McCord, V. Sick, G. Stokes, P. Styring. Dimethyl ether synthesis via captured $\mathrm{CO} 2$ hydrogenation within the power to liquids concept: A techno-economic assessment. Energy Convers Manag 184:262-76 (2019) doi:10.1016/j.enconman.2019.01.046.

17 A. Hankin, N. Shah. Process exploration and assessment for the production of methanol and dimethyl ether from carbon dioxide and water. Sustain Energy Fuels 1541-56 (2017) doi:10.1039/C7SE00206H.

18 A. Crivellari, V. Cozzani, I. Dincer. Design and energy analyses of alternative methanol production processes driven by hybrid renewable power at the offshore Thebaud platform. Energy Convers Manag 187:148-66 (2019) doi:10.1016/j.enconman.2019.03.017.

19 G.A. Olah, A. Goeppert, G.K.S Prakash. Chemical recycling of carbon dioxide to methanol and dimethyl ether: From greenhouse gas to renewable, environmentally carbon neutral fuels and synthetic hydrocarbons. J Org Chem 74:487-98 (2009) doi:10.1021/jo801260f.

20 E. Catizzone, G. Bonura, M. Migliori, F. Frusteri, G. Giordano. CO2 Recycling to Dimethyl Ether: State-of-the-Art and Perspectives 1-31 (2017) doi:10.3390/molecules23010031.

21 Dimethyl Ether (DME) | METHANOL INSTITUTE n.d. https://www.methanol.org/dimethyl-ether-dme/ (accessed April 16, 2020).

22 G.A. Olah, A. Goeppert, G.K.S. Prakash. Beyond Oil and Gas: The Methanol Economy. 2nd ed. Weinheim, Germany: Wiley-VCH Verlag GmbH \& Co. KGaA; (2009) doi:10.1002/9783527627806.

23 CRI - Carbon Recycling International n.d. https://www.carbonrecycling.is/home (accessed December 18, 2019).

24 K. Atsonios, K.D. Panopoulos, E. Kakaras. Investigation of technical and economic aspects for methanol production through $\mathrm{CO} 2$ hydrogenation. Int J Hydrogen Energy 41:2202-14 (2016) doi:10.1016/j.ijhydene.2015.12.074.

25 M. Héder. From NASA to EU: The evolution of the TRL scale in Public Sector Innovation. Innov J 22:1-23 (2017).

26 FLEXCHX. Review of electrolysis technologies and their integration alternatives FLEXCHX Flexible combined production of power, heat and transport fuels from renewable energy sources 2018:35. 
27 Ursua A, Gandia LM, Sanchis P. Hydrogen Production From Water Electrolysis: Current Status and Future Trends. Proc IEEE 100:410-26 (2012) doi:10.1109/JPROC.2011.2156750.

28 A. Ursua, P. Sanchis. Static-dynamic modelling of the electrical behaviour of a commercial advanced alkaline water electrolyser. Int J Hydrogen Energy 37:18598614 (2012) doi:10.1016/j.ijhydene.2012.09.125.

29 M. Ni, M.K.H. Leung, D.Y.C Leung. An electrochemical model of a solid oxide steam electrolyzer for hydrogen production. Chem Eng Technol 29:636-42 (2006) doi:10.1002/ceat.200500378.

30 M. Ni, M.K.H. Leung, D.Y.C. Leung. Parametric study of solid oxide steam electrolyzer for hydrogen production. Int J Hydrogen Energy 32:2305-13 (2007) doi:10.1016/j.ijhydene.2007.03.001.

31 F. Lonis. Design, modelling, evaluation and comparison of energy systems for the production and use of renewable methanol using recycled $\mathrm{CO} 2$. $\mathrm{PhD}$ thesis. University of Cagliari, 2020.

32 F. Lonis, V. Tola, G. Cau. Renewable methanol production and use through reversible solid oxide cells and recycled CO2 hydrogenation. Fuel 246:500-15 (2019) doi:10.1016/j.fuel.2019.02.108.

33 L. Barelli, G. Bidini, G. Cinti. Airflow Management in Solid Oxide Electrolyzer (SOE) Operation: Performance Analysis. ChemEngineering 1:13 (2017) doi:10.3390/chemengineering1020013.

34 É.S. Van-Dal, C. Bouallou. Design and simulation of a methanol production plant from CO2 hydrogenation. J Clean Prod 57:38-45 (2013) doi:10.1016/j.jclepro.2013.06.008.

35 K.I.M. Al-Malah. Aspen Plus ${ }^{\circledR}$. Hoboken, NJ, USA: John Wiley \& Sons, Inc.; (2016). doi:10.1002/9781119293644.

36 O. Schmidt, A. Gambhir, I. Staffell, A. Hawkes, J. Nelson, S. Few. Future cost and performance of water electrolysis: An expert elicitation study. Int J Hydrogen Energy 42:30470-92 2017 doi:10.1016/j.ijhydene.(2017).10.045. 